\title{
The development of the Primary Care Clusters Multi-dimensional Assessment (PCCMA): a mixed-methods study
}

Stanciu, Marian; Law, Rebecca-Jane; Myers, Paul; Parsonage, Rachel; Hiscock, Julia; Williams, Nefyn; Wilkinson, Clare

\section{Health Policy}

DOI:

10.1016/j.healthpol.2019.12.004

Published: 01/02/2020

Peer reviewed version

Cyswllt i'r cyhoeddiad / Link to publication

Dyfyniad o'r fersiwn a gyhoeddwyd / Citation for published version (APA):

Stanciu, M., Law, R-J., Myers, P., Parsonage, R., Hiscock, J., Williams, N., \& Wilkinson, C. (2020). The development of the Primary Care Clusters Multi-dimensional Assessment (PCCMA): a mixed-methods study. Health Policy, 124(2), 152-163.

https://doi.org/10.1016/j.healthpol.2019.12.004

\footnotetext{
Hawliau Cyffredinol / General rights

Copyright and moral rights for the publications made accessible in the public portal are retained by the authors and/or other copyright owners and it is a condition of accessing publications that users recognise and abide by the legal requirements associated with these rights. study or research

- Users may download and print one copy of any publication from the public portal for the purpose of private

- You may not further distribute the material or use it for any profit-making activity or commercial gain

- You may freely distribute the URL identifying the publication in the public portal?
}

Take down policy

If you believe that this document breaches copyright please contact us providing details, and we will remove access to the work immediately and investigate your claim. 
The Primary Care Clusters Multidimensional Assessment (PCCMA)

The development of the Primary Care Clusters Multi-dimensional Assessment (PCCMA): a mixed-methods study

DOI: $\underline{\text { 10.1016/j.healthpol.2019.12.004 }}$

\section{Authors:}

Marian Andrei Stanciu ${ }^{1,2}$

Rebecca-Jane Law ${ }^{1}$

Paul Myres ${ }^{3}$

Rachel Parsonage ${ }^{1}$

Julia Hiscock ${ }^{1}$

Nefyn Williams ${ }^{4}$

Clare Wilkinson ${ }^{1}$

${ }^{1}$ North Wales Centre for Primary Care Research, Bangor University, United Kingdom

${ }^{2}$ School of Medicine, Faculty of Medicine and Health Sciences, University of Nottingham, United Kingdom

${ }^{3}$ Public Health Wales, Cardiff, United Kingdom

${ }^{4}$ Department of Health Services Research, University of Liverpool, Liverpool, United Kingdom

Competing Interests. None.

\section{Acknowledgements.}

We would like to thank Dionne Kringos for allowing us to base our methodological development process and the Primary Care Clusters Multi-dimensional Assessment (PCCMA) framework on her previous work on the European Primary Care Monitor (PC Monitor) project. We would also like to thank Maggie Hendry and Diana Pasterfield for their early contribution to Work Package 2, and Alun Surgey for his help analysing the Work Package 3 data and drafting the final PCCMA items. We are particularly grateful to our funder (Public Health Wales), and to key professionals and managers who were instrumental in promoting our work during its development and enabling us to achieve the recruitment targets. Lastly, and most importantly, we would like to thank the many clinicians and managers at all levels of the National Health Service in Wales, who participated in Work 
The Primary Care Clusters Multidimensional Assessment (PCCMA)

Packages 1, 3, and 4, and contributed with their expertise to the development and application of the PCCMA.

\begin{abstract}
A strong primary care (PC) system is essential for an efficient and high-quality healthcare service. Many countries have adopted a model of PC that encourages different healthcare providers to work together, at scale, in multidisciplinary/multiagency teams (PC clusters). The aim of the present work was to develop a quantitative instrument for the systematic and comprehensive assessment of PC clusters. This was a non-experimental, mixed-methods study grouping four work packages (WP), and involving PC cluster leads and a wide range of key stakeholders from across Wales. Interviews with 22 PC cluster leads (34\%) investigated the clusters' functioning (WP1). A systematic review identified relevant PC assessment frameworks and instruments (WP2). An expert group reviewed the evidence and drafted the new assessment tool, further evaluated and amended in two stakeholder workshops (WP3). Thirty-eight cluster leads (62\%) completed the newly developed online assessment (WP4). The final instrument consisted of 53 indicators, across 11 systemic dimensions of PC and produced a comprehensive assessment of the functioning of PC clusters in Wales. This rigorous early development of an innovative instrument to evaluate PC at a scaled-up (cluster) level (particularly in the format of a 360-degree assessment) can inform healthcare policy decisions regarding the expansion and ongoing adjustment of the model in response to local needs and challenges.
\end{abstract}

\title{
Highlights
}

- Developed primary care services encourage providers to work together in multidisciplinary clusters

- Primary care clusters assessment is incipient, but comparable frameworks and instruments exist

- The present novel instrument allows the quantitative assessment of primary care clusters

- The instrument could be further developed for '360-degrees assessment' of clusters 
The Primary Care Clusters Multidimensional Assessment (PCCMA)

\section{Introduction}

Effective and comprehensive primary care (PC) services are the foundation for an efficient, equitable and cost-effective healthcare service. Many case studies suggest that PC strength improves when provider organisations are 'scaled up' to cover population groups of 20-50,000 patients, allowing different health professions, providers and patient representatives to work closer together in multidisciplinary teams in the community.[1-3] These models can include general practitioners, nurses, pharmacists, physiotherapists, ophthalmologists, dental professionals, social care services, third sector providers and others working together to coordinate and support each other's activity providing care and health services for the same population in a restricted geography. Variants of this model of PC exist in Spain,[4] Italy,[5] Alberta in Canada,[6] Sweden,[7] Australia,[8-9], and the United Kingdom (UK).[10-11] We will refer to these structures as "primary care clusters", in order to simplify the varied nomenclature used to identify them.

Presently, there remains a lack of evidence for the impact of PC clusters, in particular regarding structural aspects of PC that benefit the most from working in clusters. This evidence is needed to inform the implementation and future development of the PC clusters policy. Comprehensive frameworks and instruments to assess primary healthcare services at a national level already exist, but they do not specifically measure the performance of PC clusters.[1214] Historically, such frameworks and instruments have been developed to compare healthcare provision between countries, $[12,15,16]$ but also to help monitor health reform efforts and guide quality improvement in primary care.[17] Key dimensions of such frameworks (e.g., regional autonomy, continuity of care, coordination of care, and community orientation) were associated with improved health outcomes.[17] Therefore, although existing instruments are not expected to reflect the characteristics of the current structures of PC clusters, their associated frameworks and dimensions of analysis can inform the development of PC clustersspecific quantitative assessment tools.

On the most granular level of analysis, instruments to assess the performance of individual general practices have also been developed,[18-19] and reviewed,[20-21] but they do not reflect the functional nature and the multidisciplinary character of PC clusters. Most notably, the Primary Care Assessment Tool (PCAT) measures the quality of health care at the level of individual providers, using a basic framework of established PC principles, such as community focus, continuity, comprehensiveness and accessibility of care.[22] 
The Primary Care Clusters Multidimensional Assessment (PCCMA)

An intermediate level of assessment, between the macro-level of PC systems and the micro-level of individual general practices, already exists, in the form of the Clinical Commissioning Groups (CCGs) in England, which involve cooperation between GPs and the delivery of community services. Healthcare expenditure in England is managed locally by 196 CCGs, [23-24] which consist of all the general practices within predefined geographical areas. The CCGs have a role in commissioning secondary and community care for populations ranging from 100,000-900,000 patients. At the same time, the GPs' own funding and all PC services are managed by NHS England directly through 27 area teams, but CCGs can commission additional community-based services from its member practices.[25] The CCGs are much larger structures than PC clusters, in terms of the population served and the broad commissioning remit, but like PC clusters involve the cooperation between GPs and other local agencies, as well as the planning community services. Importantly, CCGs benefit from a developed assessment programme, which can inform the assessment of PC clusters.

NHS England conducts an annual assessment of every CCG,[25] using the Improvement and Assessment Framework (IAF),[26] which covers four domains related to a limited range of health priorities: better care, better health, sustainability and leadership. NHS England has also commissioned a 360 degree CCG stakeholder survey to allow feedback on their working relationships and organisational development. The main topic areas covered by this survey include overall engagement of stakeholders, working relationships, plans and priorities and CCG leadership. However, the unit of assessment is always the CCG (whose primary activity is commissioning secondary care services), and are not functionally similar to PC clusters. In addition, neither assessment is designed to reflect a holistic perspective of PC in England, which means that while specific short-term targets are monitored, important aspects of the PC system such as continuity of care, workforce development and equity of care could be overlooked.

Health care is a devolved sector in the United Kingdom, being planned, managed and funded separately in England, Wales, Scotland, and Northern Ireland. In England, within many of the CCGs, smaller locality groups (ranging from 4-23 general practices and serving 75,000200,000 patients) help identify local priorities and are allocated an annual budget by their CCG, as well as the ability to reinvest any unspent funds in local priorities.[27] Until recently, these smaller locality groups could have been compared to the PC clusters in Wales and also in Scotland, but they did not function in every CCG in England, and were not systematically assessed at a national level. Since July 2019, NHS England has introduced 1259 geographical structures, akin to PC clusters, called Primary Care Networks (PCNs).[28] The PCNs will be 
The Primary Care Clusters Multidimensional Assessment (PCCMA)

required from 2020 to deliver prescribed national service specifications (e.g., supporting early cancer diagnosis, personalised care, structured medication reviews, enhanced health in care homes).[29]

In Scotland, all GP practices are part of one of 147 PC clusters of different sizes, depending on local circumstances and geography since 2017/2018.[30-31] Typically, PC clusters includes four to eight practices covering 20,000-40,000 patients.

All general practices in Northern Ireland joined one of 17 fully incorporated GP Federations, established as a community interest company (CIC), limited by guarantee in the not-for-profit sector. GP federations are owned entirely by GPs, and, each serves approximately 100,000 patients and is made up of around 20 practices.[32] Northern Ireland is the only part of the United Kingdom that has a unified model of Federations governed by a unified Members Agreement covering its entire population of approximately 1.8 million people.[32-33]

In Wales, 64 PC clusters covering all the general practices have been in existence since 2014. Each cluster consists of a group of general practices, other health and social care providers and third sector organisations serving populations of 20,000-100,000.[14,34] Cluster leads are most commonly GPs, but also include a nurse practitioner and a third sector community co-ordinator, and are appointed by one of the seven local health boards in Wales. General practices are incentivised to participate in the cluster work, but participation is not mandatory. The aims of PC clusters in Wales are to improve the co-ordination of care, the integration of health and social care, and reduce inequalities in health.[35] Under this structure, clusters are required to agree a joint action plan (cluster network plan), addressing national health policy priorities and local health needs, in a manner specific to each cluster's context. The Welsh government provided additional funding through the local health boards to support the clusters.[36] A recent inquiry by the National Assembly for Wales into the PC clusters model identified promising examples of best practice in individual clusters across Wales,[37] but also challenges, including: the breadth of agencies participating in the clusters' work, the short term nature of cluster development funding, and their lack of legal status.[37] The inquiry concluded that achieving the systemic change envisaged for the clusters required further progress and continued support from the Welsh Government, as well as a better monitoring of the progress made, both cross-sectionally (between clusters/health boards) and longitudinally (over time).

The present work was commissioned by Public Health Wales to develop an instrument to conduct a systematic, comprehensive, and multidimensional assessment of the PC clusters, 
The Primary Care Clusters Multidimensional Assessment (PCCMA)

which is complementary to standardised clinical indicators and other routinely collected healthcare data. Methodological frameworks for the development of indicators to assess PC systems have already been developed.[12-14] The present programme of work used one of its latest formulations, developed to compare European primary case systems,[12] and adapted it to the context of PC clusters in Wales. As a starting point, this work aimed to develop an assessment instrument, called the Primary Care Clusters Multi-dimensional Assessment (PCCMA), for use by PC cluster leads, health board PC development managers, and central government healthcare planners and policy makers to evaluate and support the development of PC clusters. In the future, this instrument could be used as a 360 degrees assessment tool by a broad set of members and stakeholders.

\section{Materials and methods}

The Primary Care Clusters Multi-dimensional Assessment (PCCMA) was developed in four stages (work packages): (1) qualitative interviews with cluster leads; (2) systematic literature review of instruments to assess PC systems; (3) evaluation among PC experts and practitioners; (4) piloting of the PCCMA for the 64 clusters in Wales.

\section{Cluster Leads' views on maturity and impact of clusters (Work Package 1)}

Evaluative qualitative interviews explored the cluster leads' views on the maturity of the PC clusters, their achievements and impact, the relationship with the health board, the multidisciplinarity of the cluster, and the involvement of the cluster members in the creation and implementation of the Cluster Action Plan. The leads of all 64 PC clusters in Wales were invited by email to take part in semi-structured telephone interviews. Two reminder emails were sent to non-responders. Twenty-two cluster leads ( 7 female; 15 male) from all seven health boards in Wales completed the interviews, representing $34 \%$ of all PC clusters, including clusters small and large ranging from 3-15 general practices. Most cluster leads were GPs $(\mathrm{N}=20)$, one was a Nurse Practitioner and another was a Third Sector Community Co-ordinator. The interviews were conducted between February and April 2016, by MAS a non-clinical researcher. A topic guide was used and interviews were audio recorded and transcribed. The Framework method of data analysis was chosen for its transparency and suitability for applied policy research such as this.[38] The analysis was conducted by two members of the research team with different disciplinary backgrounds (MAS and R-JL) to enhance reliability. The 
systematic, five-stage matrix based process of the Framework approach was followed including identifying a thematic framework, indexing and charting participants' responses, and interpretation of trends and patterns in the data.[39] This allowed analysis both by theme and by case and involved multidisciplinary members of the research team.

\section{Literature review of PC assessment models (Work Package 2)}

We updated a previous systematic review,[40] to describe the core systemic dimensions of PC and assess their relevance to outcomes. We appraised their list of included studies to identify if any met our inclusion criteria, modified their search strategy to narrow its scope and meet the needs of our review (in effect, focusing on a subset of studies relating to PC assessment frameworks and instruments). Since their searches were completed in 2008, we limited our searches to January 2008 - September 2016. The search strategy (see Appendix 1) was developed in Medline and adapted for the remaining databases (Embase, Cochrane Library, CINAHL, King's Fund database, IDEAS database and EconLit).

Included studies were set in countries with PC systems comparable to that in the UK and focussed on measuring or evaluating the impact of PC systems. The method of measurement or evaluation had to be fully described. We limited inclusion to studies published in full, in the English language, and excluded studies that focussed on low-income countries as well as those that reported condition-specific measurement tools, patient satisfaction or patient report only tools, and articles based on opinion.

Two reviewers (MAS, R-JL) independently screened the titles and abstracts for eligibility, and assessed the full texts subsequently retrieved for inclusion. Discrepancies were settled by a third reviewer $(\mathrm{CW})$. Data abstracted from the included studies were: setting, sample size, study design, study aims and focus, method or tool of assessment and focus of evaluation. Results were tabulated and described narratively.

The development of the Primary Care Clusters Multi-dimensional Assessment (PCCMA) tool (Work Package 3)

The PCCMA tool was developed starting from potential PC indicators identified in the cluster leads interviews (Work Package 1) and the frameworks identified in the literature review (Work Package 2). An expert group (including two academic healthcare researchers with experience in the development and validation of quantitative instruments and three 
academic GPs with senior management experience at regional and national level) reviewed and drafted a novel pool of PC indicators. The development of the PCCMA tool focused on comprehensiveness, content and clarity. The comprehensiveness of the PCCMA instrument was addressed by mapping the newly developed indicators onto the assessment framework with the broadest scope among those of the developed PC systems reviewed, and the creation of novel dimensions was considered - especially related to the introduction of the PC clusters. Regarding the content of each dimension, in three separate iterations, the indicators were collectively assessed by the expert group with two aims: (1) to fully cover the domain of each dimension, with minimum overlap between indicators; and (2) to achieve a similar spread of content between indicators (i.e., to avoid one indicator being very general and another being very specific, within the same dimension). The process involved drafting new indicators, and merging or splitting other indicators. The priority was to balance the indicators within each dimension, acknowledging that systemic dimensions may vary between them, both in breadth and density of indicators. The clarity of the indicators was considered during each iteration, and further addressed during the subsequent two stakeholder consultation workshops and online pilot/feedback.

All PCCMA indicators consisted of a statement, requiring a rating using a similar electronic visual analogue scale (eVAS), from 0-100. Each eVAS rating was aided by three anchors: one at either end, and the middle of the 0-100 scale. Anchors are specific to the indicators, thus are often different between indicators, but particular care was taken in the choice of anchors. Firstly, as is usual to avoid a floor/ceiling effect, the end anchors had to be an absolute minimum and maximum for the indicator, such that no rating below or above, respectively, was conceivably possible. Secondly, where appropriate, the middle anchor had to represent a situation relatively equal to the two ends of the scale, and, critically, had to contain specific elements relating to the indicator. This requirement was aimed at reducing the tendency of responders to provide a middle-of-the-range rating, except when the specific situation described by the anchor was actually occurring in practice (see Figure 1). 
The Primary Care Clusters Multidimensional Assessment (PCCMA)

In our cluster, engagement of all relevant health and social care providers in cluster activity is...
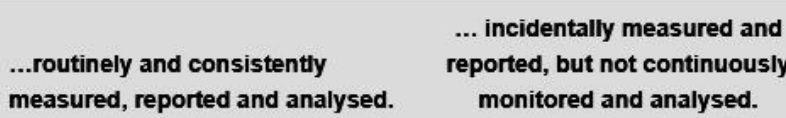

Figure 1. Sample PCCMA indicator (engagement of all relevant health and social care providers) and its associated electronic Visual Analogue Scale (eVAS) showing an arbitrary rating of 60 and its visual relationship to the three eVAS anchors.

Two additional workshops with a broad representation of PC cluster stakeholders $(N=39$; see Table 1) were organised to further refine the PCCMA tool.

Table 1. Categories of participants at the two stakeholders' workshops to refine the indicators of the Primary Care Clusters Multi-dimensional Assessment (PCCMA).

\begin{tabular}{lc}
\hline Stakeholder categories & Number of participants \\
\hline Cluster Leads & 3 \\
\hline Health Board - Assistant Medical Director & 3 \\
\hline Health Board - Deputy CEO & 1 \\
\hline Health Board - Head of Primary Care & 3 \\
\hline Health Board - Senior Cluster Coordinator & 2 \\
\hline Health Board - Primary care & 8 \\
\hline Health Inspectorate Wales & 1 \\
\hline Nursing & 3 \\
\hline Optometry & 2 \\
\hline Patient representative & 1 \\
\hline Pharmacy & 1 \\
\hline Public Health Wales & 4 \\
\hline Social Services & 2 \\
\hline Third sector organisations & 3 \\
\hline Wales Centre for Primary and Emergency Care Research (PRIME) & 2 \\
\hline Total & 39 \\
\hline
\end{tabular}

The stakeholder workshops were located in South Wales (Cardiff) and in North Wales (Wrexham). During the workshops, in the first part of each session, participants worked in groups of 8-10 to review the previously devised indicators. Comments (including drafting, rewording or re-allocation of indicators between dimensions of PC) were collected in writing, 
The Primary Care Clusters Multidimensional Assessment (PCCMA)

and reported back to the group for discussion in the second part of the two sessions. The workshops were audio recorded. After the workshop, the multidisciplinary expert group collated all workshop comments and online feedback and build consensus through discussion regarding the final wording of the indicators to finalise the PCCMA instrument.

The first application of the Primary Care Clusters Multi-dimensional Assessment (PCCMA) tool (Work Package 4)

Between June-August 2017, cluster leads representing 40 clusters from all seven health boards in Wales, completed the PCCMA survey online. All questions were presented using an electronic visual analogue scale (eVAS), whose slider could be positioned anywhere within the answer range (0-100). The indicators were presented in succession, without any mention of the 11 dimensions or the three levels of the PCCMA. Twenty-eight of the 53 questions were reverse scored to reduce possible response bias (see Figure 1). Summary PCCMA dimension scores were calculated as means of their respective indicator ratings. Similarly with the PC Monitor,[12] summary scores were classed into three groups: "low" (0-33), "medium" (33-66), and "high" (66-100), which corresponded visually to the three anchors of the eVAS. Analyses were carried out for the PCCMA systemic dimensions and in an anonymised form for the clusters, using descriptive statistics, to investigate the distribution of scores. Firstly, the analysis aimed to establish whether the PCCMA was able to differentiate between low, medium and high performing situations for all dimension, thus avoiding floor/ceiling effects and middle-of-the-road ratings. Secondly, we investigated any differences between the strength of individual PC clusters. However, since only the cluster lead from each cluster provided ratings on the PCCMA, the cluster analysis was reported in an anonymised format, and did not include detailed individual or summary scores for each cluster, but distribution of scores consisting of ranges from minimum to maximum summary scores for individual PCCMA dimensions.

\section{Results}

Cluster Leads' views on maturity and impact of clusters (Work Package 1)

Cluster leads suggested that clusters had the opportunity to enhance local PC services, despite administrative barriers to their relationship with health boards and occasional 
difficulties in engaging with other community agencies (see Table 2). Interestingly, cluster leads reported that sometimes service development initiatives of PC clusters appeared to clash with the health board's own development plan for that area, and eventually, the cluster's initiatives failed to access their dedicated funding or had to be replaced with other initiatives. Moreover, key departments within health boards seemed to view some clusters as more developed than others; and cluster leads believed that these perceptions influenced the speed and ease with which clusters accessed their funding.

A few cluster leads reported a high engagement of GPs in the cluster work, while others said the GPs' participation was still low. Sometimes, when cluster leads reported a high overall engagement, they then explained that only some GPs were very active while others were still very reluctant to get involved. Achievements were often limited by the lack of cluster autonomy, lack of timely access to funding, inadequate administrative arrangements and other bureaucratic delays. However, cluster leads were able to identify many innovative projects across Wales. There was uncertainty about the future of clusters and their funding arrangements. Despite occasional local innovations, the use of patient-level data was underdeveloped. Commonly suggested areas for improvement included increased funding to PC overall, the need to address the underlying GP staffing crisis, a call for increased governance and autonomy, new models for staff sharing, a call for measurements of cluster impact, a need for technical and leadership support, and suggestions for a best practice sharing programme across Wales. Although the interviews covered a comprehensive range of topics related to the functioning of PC clusters, they only reflected the views of a sample of cluster leads (approximately 33\%). 
The Primary Care Clusters Multidimensional Assessment (PCCMA)

Table 2. Summary of themes and sub-themes emerging from the perspective of Cluster Leads interviews (Work Package 1).

\begin{tabular}{|c|c|}
\hline Themes and sub-themes & Key findings \\
\hline $\begin{array}{l}\text { Theme } 1 . \text { The emergence of } \\
\text { primary clusters and the } \\
\text { involvement of GPs in cluster- } \\
\text { level planning }\end{array}$ & $\begin{array}{l}\text { 1. The participation of individual General Practitioners (GPs) in cluster work was considerably } \\
\text { variable. } \\
\text { 2. Some local GPs showed a high level of enthusiasm and engagement in cluster work. } \\
\text { 3. Practice Managers had a key contribution in the involvement of GPs. } \\
\text { 4. Information about the purpose and opportunities of primary care clusters were not fully } \\
\text { disseminated. } \\
\text { 5. Historical working arrangements influenced the engagement of GPs in cluster work. } \\
\text { 6. The heavy workload of GPs was often a barrier to greater engagement in primary care clusters. }\end{array}$ \\
\hline $\begin{array}{l}\text { Theme } 2 . \text { The } \\
\text { multidisciplinarity of the } \\
\text { clusters and their ability to } \\
\text { implement effective cross- } \\
\text { agency working }\end{array}$ & $\begin{array}{l}\text { 1. The engagement of different agencies across clusters is varied, and this reflects local work } \\
\text { arrangements and the level of service development. } \\
\text { 2. The perceived low degree of clusters autonomy restricted their ability to engage in multiagency } \\
\text { work. }\end{array}$ \\
\hline $\begin{array}{l}\text { Theme } 3 \text {. The relationship } \\
\text { between the primary care } \\
\text { clusters and Local Health } \\
\text { Boards }\end{array}$ & $\begin{array}{l}\text { 1. Local governance and decentralisation of primary care delivery is variable. } \\
2 \text { Clusters faced functional difficulties in their relationship with the health boards' finance and } \\
\text { human resources departments. } \\
\text { 3. Communication between primary care clusters and health boards was hampered by a relatively } \\
\text { reduced awareness of the clusters' role in the health boards, increased workload pressures on both } \\
\text { sides and unfamiliar work processes. } \\
\text { 4. Communication between primary care clusters and health boards was aided by existing } \\
\text { departments within the health boards taking an extended role. } \\
\text { 5. Cluster Leads were looking for more financial and administrative support from health boards. }\end{array}$ \\
\hline $\begin{array}{l}\text { Theme } 4 \text {. Local risk } \\
\text { stratification and collective } \\
\text { pooling of patient data at cluster } \\
\text { level to identify local priorities } \\
\text { and plan local services }\end{array}$ & 1. Engagement with the patient data locally was underdeveloped. \\
\hline
\end{tabular}


The Primary Care Clusters Multidimensional Assessment (PCCMA)

\begin{tabular}{|l|l|}
\hline Theme 5. Recommendations & $\begin{array}{l}\text { 1. The transfer of care from secondary care into the community. } \\
\text { from Cluster Leads on assessing } \\
\text { and improving the clusters' } \\
\text { structure and functioning }\end{array}$ \\
$\begin{array}{l}\text { 3. The impact of the clusters on the sustainability of primary care (for example, by sharing staff). } \\
\text { 4. The ability of the clusters to demonstrate to stakeholders and partners the impact they are having } \\
\text { on patient care in the community. } \\
\text { 5. The level of technical and educational support needed and received by clusters to develop new } \\
\text { ways of working locally. }\end{array}$ \\
\hline
\end{tabular}


The Primary Care Clusters Multidimensional Assessment (PCCMA)

Literature review of PC assessment models (Work Package 2)

Database searches identified 9,652 publications. After removing 1,582 duplicate records, the titles of 8,070 publications were screened, then the full text of 20 publications was retrieved and assessed for eligibility. Six studies met the inclusion criteria and were included in the qualitative synthesis (see Figure 2).

Figure 2. PRISMA diagram of the literature search and selection process

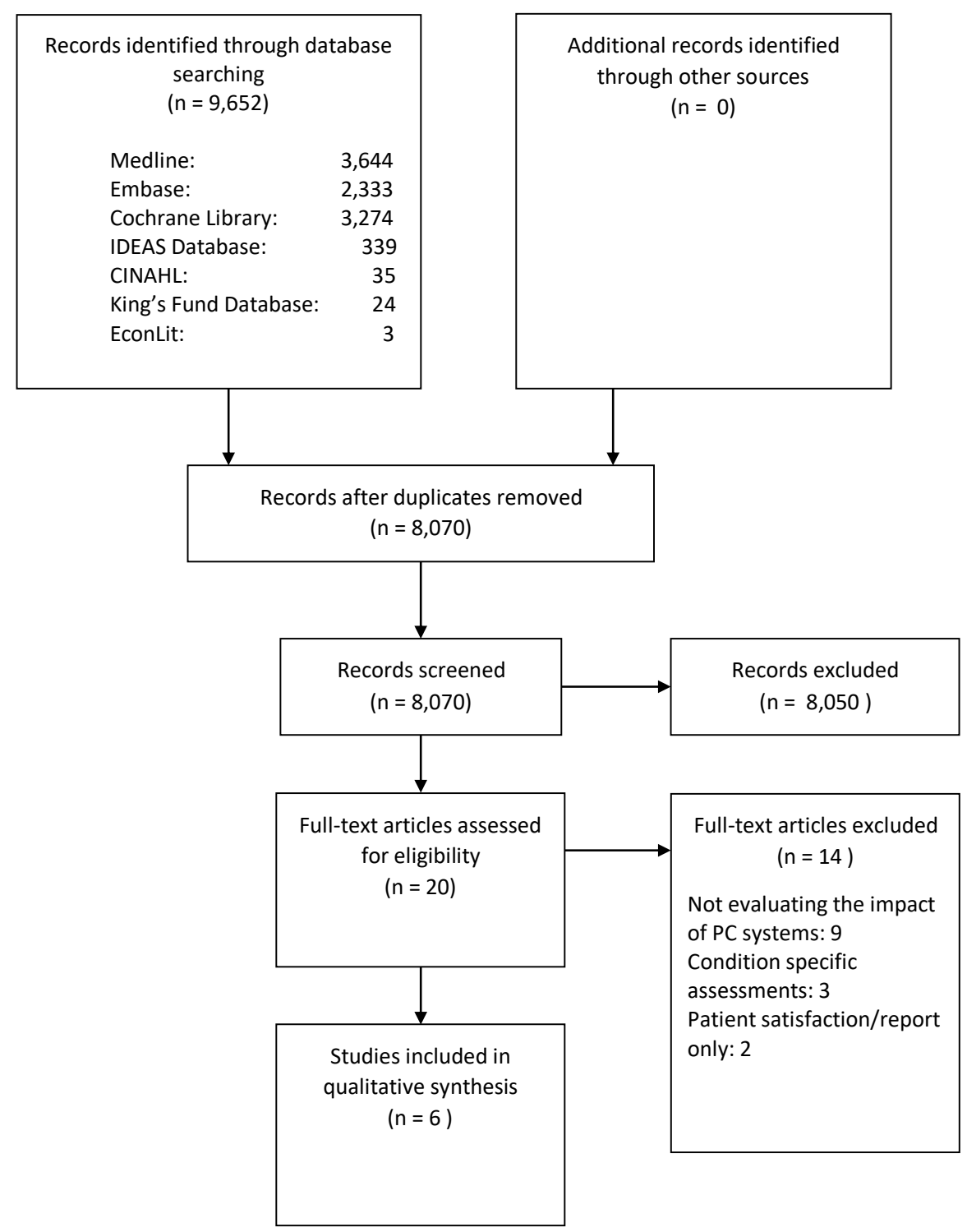


The Primary Care Clusters Multidimensional Assessment (PCCMA)

The review identified a landmark study (PC Monitor) assessing the strength of PC across the European countries,[12] and five further reports of instruments able to measure aspects of PC systems. The PC Monitor benefited from the most comprehensive framework from the studies included in the review, and informed the development of the PCCMA tool. The remaining studies employed only a subset of the PC Monitor dimensions (see Table 3), but provided insight into how the assessment framework could be further improved (e.g., to reflect organisation level indicators - later to be included in the novel "cluster organisation" dimension). Moreover, a pool of indicators was collated from all included studies, which fed into the development of novel PCCMA indicators in Work Package 3. 
The Primary Care Clusters Multidimensional Assessment (PCCMA)

Table 3. Characteristics of studies included in the literature review of PC assessment models (Work Package 2).

\begin{tabular}{|c|c|c|c|c|c|c|c|c|}
\hline Author(s) & Year & Country & Sample & Study design & Study aim and focus & Method/tool of assessment & Validation & Framework of assessment \\
\hline $\begin{array}{l}\text { Amando \& } \\
\text { dos Santos }\end{array}$ & 2009 & Portugal & $\begin{array}{l}\text { Data from all } \\
\text { Portuguese } \\
\text { health centres (n } \\
=351) \text { between } \\
2004 \text { and } 2005 \\
\text { (researcher } \\
\text { completed) } \\
\end{array}$ & $\begin{array}{l}\text { Cross- } \\
\text { sectional, } \\
\text { survey-based }\end{array}$ & $\begin{array}{l}\text { To compare the geographical } \\
\text { equity of access to services, } \\
\text { technical efficiency and } \\
\text { quality of } \\
\text { services across district health } \\
\text { authorities }\end{array}$ & $\begin{array}{l}\text { Percentage of registered } \\
\text { patients who have } \\
\text { a designated family doctor to } \\
\text { assess equity. Data } \\
\text { envelopment analysis to } \\
\text { assess technical efficiency. }\end{array}$ & $\begin{array}{l}\text { Routinely collected } \\
\text { data (Instituto de } \\
\text { Gestão Informática e } \\
\text { Financeira da } \\
\text { Saúde) }\end{array}$ & $\begin{array}{l}\text { Equity, efficiency and quality of } \\
\text { services }\end{array}$ \\
\hline $\begin{array}{l}\text { Beaulieu et } \\
\text { al. }\end{array}$ & 2013 & $\begin{array}{l}\text { PC practices } \\
\text { from } \\
3 \text { regions of } \\
\text { Quebec, } \\
\text { Canada }\end{array}$ & $\begin{array}{l}\text { A stratified } \\
\text { random } \\
\text { sample of } 37 \\
\text { PC physicians }\end{array}$ & Survey-based & $\begin{array}{l}\text { To identify the } \\
\text { organizational characteristics } \\
\text { of primary care } \\
\text { practices that provide high- } \\
\text { quality PC }\end{array}$ & $\begin{array}{l}\text { Organisational characteristics } \\
\text { using a validated } \\
\text { questionnaire and the Team } \\
\text { Climate Inventory. }\end{array}$ & $\begin{array}{l}\text { Survey instruments } \\
\text { validated in French } \\
\text { and English }\end{array}$ & $\begin{array}{l}\text { Identifying organizational } \\
\text { characteristics associated with quality } \\
\text { of care }\end{array}$ \\
\hline Kringos et al. & 2013 & $\begin{array}{l}27 \text { EU } \\
\text { member } \\
\text { states, plus } \\
\text { Iceland, } \\
\text { Norway, } \\
\text { Switzerland } \\
\text { and Turkey }\end{array}$ & $\begin{array}{l}31 \text { countries } \\
\text { (researcher } \\
\text { completed) }\end{array}$ & $\begin{array}{l}\text { International } \\
\text { comparative } \\
\text { cross- } \\
\text { sectional } \\
\text { study }\end{array}$ & $\begin{array}{l}\text { Evaluation of strength of } \\
\text { primary care in Europe }\end{array}$ & $\begin{array}{l}\text { The European Primary Care } \\
\text { Monitor consisted of a mix of } \\
\text { quantitative and qualitative } \\
\text { indicators extracted from } \\
\text { international databases, } \\
\text { scientific publications, } \\
\text { national statistics offices, } \\
\text { healthcare stakeholders, and } \\
\text { national experts. }\end{array}$ & $\begin{array}{l}\text { Reliability } \\
\text { coefficients ( } 0.53 \text { to } \\
0.57) \text { with only two } \\
\text { scales (economic } \\
\text { conditions and } \\
\text { continuity of care) } \\
\text { scoring lower }(0.26 \\
\text { and } 0.35 \\
\text { respectively) }\end{array}$ & $\begin{array}{l}\text { Two levels with seven dimensions } \\
\text { of primary care (level } 1 \text { - structure: } \\
\text { governance, economic conditions, } \\
\text { workforce } \\
\text { development; } \\
\text { level } 2 \text { - process: accessibility, } \\
\text { comprehensiveness, continuity, and } \\
\text { coordination }\end{array}$ \\
\hline $\begin{array}{l}\text { Levesque et } \\
\text { al. }\end{array}$ & 2010 & $\begin{array}{l}\text { Quebec, } \\
\text { Canada }\end{array}$ & $\begin{array}{l}\text { Randomly- } \\
\text { selected adult } \\
\text { patients from } \\
\text { two populous } \\
\text { regions in the } \\
\text { province of } \\
\text { Quebec } \\
\end{array}$ & $\begin{array}{l}\text { Organizationa } \\
\text { 1-level data } \\
\text { from a survey } \\
\text { of } 665 \text { PHC } \\
\text { clinics }\end{array}$ & $\begin{array}{l}\text { To assess the performance of } \\
\text { PC models and the } \\
\text { organisational factors } \\
\text { associated with the high } \\
\text { performance of PC } \\
\text { organisations }\end{array}$ & $\begin{array}{l}\text { Organizational-level data } \\
\text { from a survey of PC } \\
\text { clinics and contextual-level } \\
\text { information from a survey of } \\
\text { Local Centres. }\end{array}$ & $\begin{array}{l}\text { Previously validated } \\
\text { in } 2005 \text { and } 2007\end{array}$ & $\begin{array}{l}\text { Magnitude and direction of } \\
\text { organisational change; Association of } \\
\text { organisational change with the } \\
\text { implementation of Local Networks } \\
\text { and indicators of PHC performance } \\
\text { (coverage, process and outcomes of } \\
\text { care) }\end{array}$ \\
\hline Schafer et al. & 2013 & $\begin{array}{l}\text { Belgium, the } \\
\text { Netherlands } \\
\text { and Slovenia }\end{array}$ & $\begin{array}{l}\text { Convenience } \\
\text { sample of } \sim 30 \\
\text { GPs invited, } \\
112 \text { patient } \\
\text { questionnaires } \\
\text { completed }\end{array}$ & $\begin{array}{l}\text { Questionnaire } \\
\text { development } \\
\text { and pilot } \\
\text { survey }\end{array}$ & $\begin{array}{l}\text { To explore the measurement } \\
\text { of primary health care } \\
\text { systems quality, cost, and } \\
\text { equity }\end{array}$ & $\begin{array}{l}\text { GP questionnaire to assess } \\
\text { structural aspects and care } \\
\text { processes of PC. Practice } \\
\text { questionnaire } \\
\text { to assess practice } \\
\text { characteristics }\end{array}$ & $\begin{array}{l}\text { The four } \\
\text { questionnaires are } \\
\text { based on existing, } \\
\text { validated } \\
\text { questionnaires } \\
\text { and tested through a } \\
\text { pilot survey }\end{array}$ & $\begin{array}{l}\text { Structural aspects of PC (e.g. } \\
\text { economic conditions) and care } \\
\text { processes (e.g. comprehensiveness of } \\
\text { services in PC). }\end{array}$ \\
\hline $\begin{array}{l}\text { Szecsenyi et } \\
\text { al. }\end{array}$ & 2011 & Germany & $\begin{array}{l}204 \text { PC } \\
\text { practices (all } \\
\text { practice staff, } \\
\text { e.g., GPs, } \\
\text { Practice } \\
\text { Managers, etc.) }\end{array}$ & $\begin{array}{l}\text { Repeated- } \\
\text { measures } \\
\text { study } \\
\text { (baseline and } \\
\text { three years } \\
\text { later) }\end{array}$ & $\begin{array}{l}\text { To determine whether } \\
\text { improvements in practice } \\
\text { management occurred } \\
\text { in general practices that } \\
\text { completed the European } \\
\text { Practice Assessment twice, } \\
\text { when compared to once over } \\
\text { three years }\end{array}$ & $\begin{array}{l}\text { Practice assessment } \\
\text { using the European Practice } \\
\text { Assessment (EPA) } \\
\text { instrument }\end{array}$ & $\begin{array}{l}\text { The EPA tool was } \\
\text { previously validated } \\
\text { in } 2006\end{array}$ & $\begin{array}{l}\text { Quality and safety (complaint } \\
\text { management, analysis of critical } \\
\text { incidents, safety of staff and patients, } \\
\text { quality development, quality policy, } \\
\text { and detection of quality and safety } \\
\text { problems) } \\
\text { Association between practice } \\
\text { organisation and quality } \\
\text { improvement }\end{array}$ \\
\hline
\end{tabular}

(EPA - European Practice Assessment; GP - General Practitioner; PC - Primary care; PHC - primary health care; SF-12 - 12-Item Short Form Survey) 
The Primary Care Clusters Multidimensional Assessment (PCCMA)

The development of the Primary Care Clusters Multi-dimensional Assessment (PCCMA) tool (Work package 3)

The final version of the PCCMA consisted of 53 indicators covering 11 systemic dimensions. These included the 10 dimensions of the European PC Monitor (governance, economic conditions, workforce development, access to PC, continuity of care, co-ordination of care, comprehensiveness, quality of care, efficiency of care, and equity).[12] A newly created dimension (cluster organisation) emerged from the review work (Work Package 2) and was further supported by the workshops in Work Package 3, and was also included in the PCCMA (see Table 4). 
The Primary Care Clusters Multidimensional Assessment (PCCMA)

Table 4. The systemic dimensions and indicators of the Primary Care Clusters Multi-dimensional Assessment (PCCMA).

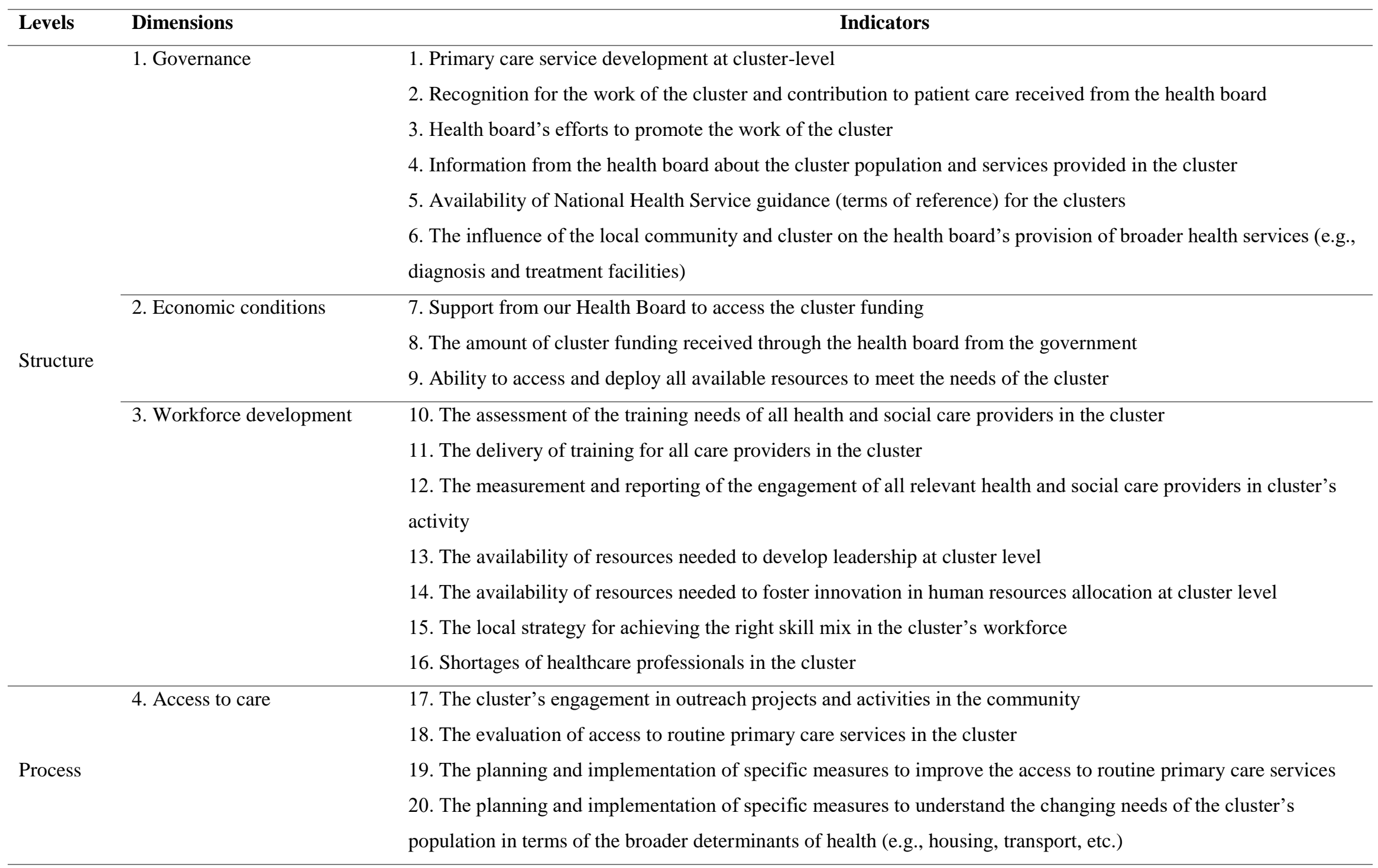


The Primary Care Clusters Multidimensional Assessment (PCCMA)

21. The planning and implementation of specific measures to influence the services provided by other agencies to meet the changing wellbeing needs of the cluster's population in terms of the broader determinants of health (e.g. planning for new builds, transport issues, etc.)

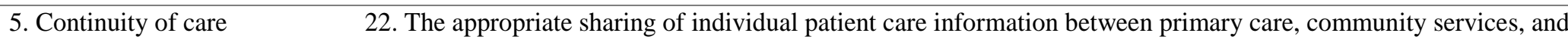
secondary care

23. The plan for the distribution of human resources and facilities within the cluster is (e.g., sharing staff when needed, such as maternity cover)

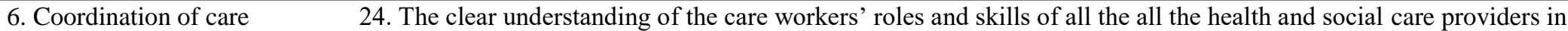
the cluster

25. The availability of care plans for patients with complex life-limiting care conditions

26. The presence of Care Coordinators / Case Managers for people with complex care needs

27. The culture of multidisciplinary working and respect between different professional disciplines

7. Comprehensiveness of care 28 . The integration and promotion of community resources (e.g., leisure centres, community groups) in the cluster's work

29. The planning and implementation of specific measures to improve end of life care

30. The planning and implementation of specific measures to improve the health and wellbeing of the cluster's population

8. Cluster organisation $\quad 31$. The use of a formalised action plan in guiding discussion at the cluster meetings

32. The breadth of participation at the cluster meetings from all health and social care providers in the cluster

33. The communication of the specific aims and actions in the cluster's action plan to all health and social care providers in the cluster

34. The contribution of patients and public to the development of our cluster's action plan

35. The participation of the health and social care providers in the cluster to the development of the cluster's action plan 
The Primary Care Clusters Multidimensional Assessment (PCCMA)

36. The planning and implementation of specific measures to encourage health and social care providers in the cluster to work more closely together

37. The planning and implementation of specific measures to share process measures and outcome data across the cluster

38. The measurement, analysis and reporting of patient orientated outcomes (patient reported outcome measures, and patient reported experience measures) across the cluster

39. The planning and implementation of specific measures to use pooled patient data to identify cluster priorities

9. Quality of care 40. The planning and implementation of quality improvement processes

41. The planning and implementation of specific measures to disseminate personalised self-management information to chronic disease patients

42. The planning and completion of specific assessments of the needs of care providers in order to prioritise actions in the cluster's action plan

43. The sharing of data on safety measures (e.g., patient safety, risk management, healthcare incident reporting, etc.) between all health and social care providers in the cluster to improve own practice and patient outcomes

44. The dissemination and promotion of evidence-based clinical guidelines (specific for primary care) to all care providers

Outcome

45. The planning and implementation of specific measures to ensure that patient-centred care is delivered by all health and social care providers

10. Efficiency of care $\quad$ 46. The planning and implementation of specific measures to promote different forms of role substitution (e.g., transferring primary care work and responsibilities from doctors to nurses, clinical pharmacists, etc.)

47. The planning and implementation of specific measures to reduce avoidable costs (e.g., shared back-office services) and streamline delivery across all providers

48. The planning and implementation of specific measures to guide the members of the public to the most appropriate service or care provider (including self-care)

49. The planning and implementation of specific measures to support the sustainability of all health and social care providers in the cluster (including contingency planning) 
The Primary Care Clusters Multidimensional Assessment (PCCMA)

11. Equity of care

50. The planning and implementation of specific measures to identify and assess local health inequalities

51. The planning and implementation of specific measures to address and improve local health inequalities

52. The planning and implementation of specific measures to consider and involve isolated communities (e.g.,

traveller communities, people with no fixed abode, refugees, etc.) in planning and provision of local primary care

services

53. The planning and implementation of specific measures to make care available through the patients' preferred

language 
The Primary Care Clusters Multidimensional Assessment (PCCMA)

The first application of the Primary Care Clusters Multi-dimensional Assessment (PCCMA) tool (Work Package 4)

The analysis of the PCCMA systemic dimensions showed that most PC clusters reported summary dimension scores in the medium range (33-66), with the sole exception of the "continuity of care" dimension, where a majority of PC clusters $(\mathrm{N}=21)$ scored in the low range (0-33), as shown in Figure 3. Firstly, this means that most cluster leads reported a moderate stage of development for their cluster, on most dimensions, which perhaps is encouraging, but not surprising. Secondly, for every single dimension, there were clusters leads who scored their own cluster high on the PCCMA scale, and others, indeed, who scored theirs very low.

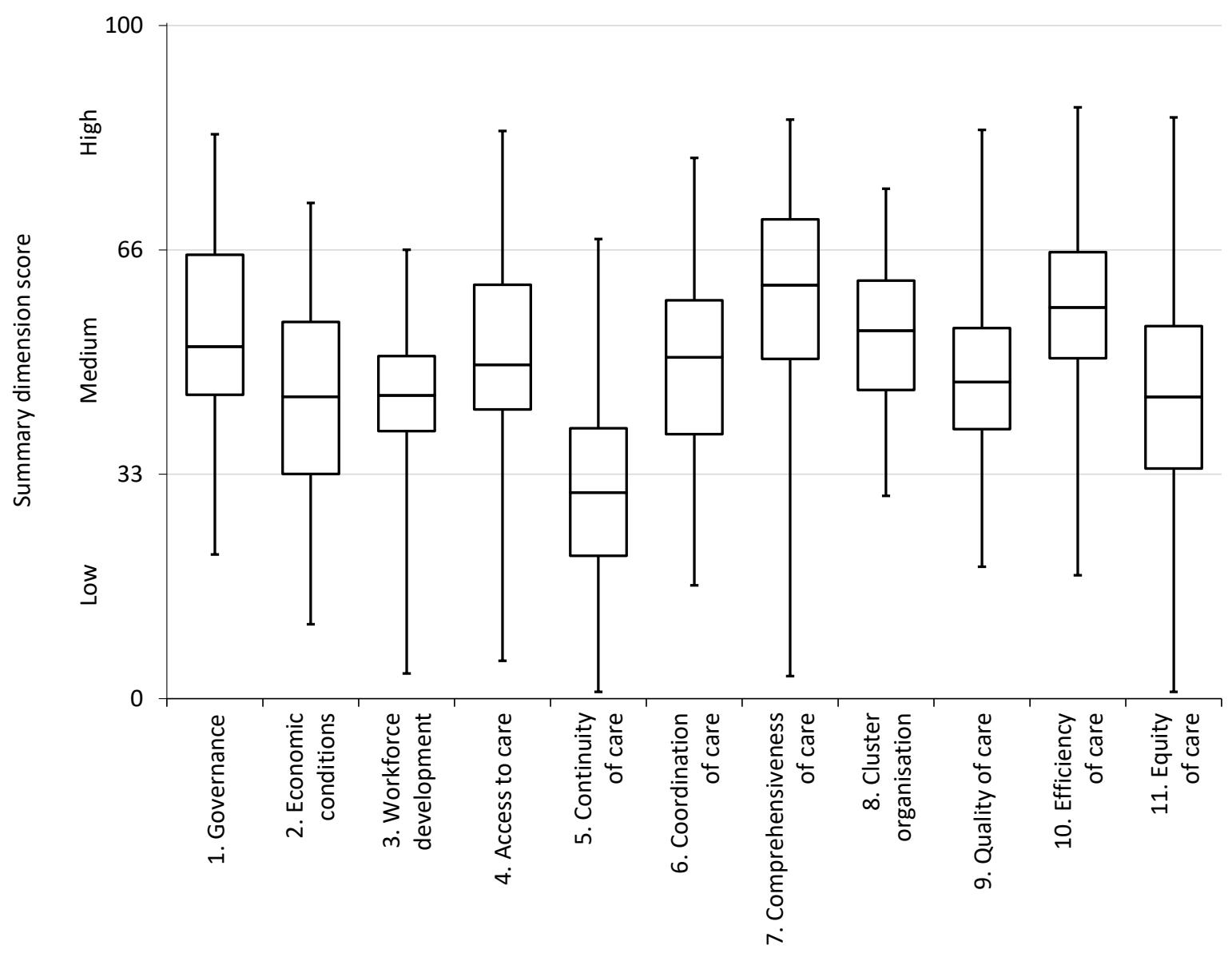

PCCA dimensions

Figure 3. Boxplots with the summary scores of the PCCMA systemic dimensions. The lower whiskers represent the range of the bottom $25 \%$ of scores (i.e., the range of summary scores 
for the lowest scoring $25 \%$ of clusters for the respective dimension); the lower part of the boxplots represents the second quartile of scores, the top part of the boxplots represents the third quartile, and the top whiskers represent the range of the top $25 \%$ of scores.

Among the structure-level dimensions, "governance" seemed to be rated highest by cluster leads. "Economic conditions" and "workforce development" dimensions were rated progressively lower. Process-level dimensions showed mixed results. There was great variability between clusters (wide range of summary scores), in particular on the "access to care" and "comprehensiveness of care" dimensions. The high scores on these systemic dimensions suggest potential cases of best practice could be identified among PC clusters, the low scores suggest more support is needed to improve the process-level dimensions of particular PC clusters. The "comprehensiveness of care" dimension was highest scoring overall, and "continuity of care" was lowest scoring. The "cluster organisation" dimension showed a notably compact range of summary scores, narrowest among all PCCMA dimensions, and closely packed around the medium range (33-66). This suggests that the practical mechanics of the cluster activity are starting to take shape across Wales, with little disparity between clusters. Outcome-level dimensions were notable for the high scores of the "efficiency of care" dimension, and the great variability of the "equity of care dimension".

The analysis of the PCCMA showed broad ranges of scores, from high to very low, on most systemic dimensions. This raised the question of whether the same clusters were responsible for all the low scores, and conversely, if other clusters were responsible for all the high scores. The analysis of the clusters was able to answer this question, and interestingly showed that while the high scores were shared between a large number of clusters (with few exceptions, from clusters numbered 13-40; see Figure 4), the very low scores were reported only by few clusters (numbered 1-3, for the lowest summary scores, and 1-15 more broadly). This indicated that efforts to support clusters may need to be targeted regionally and specifically at the affected clusters. 


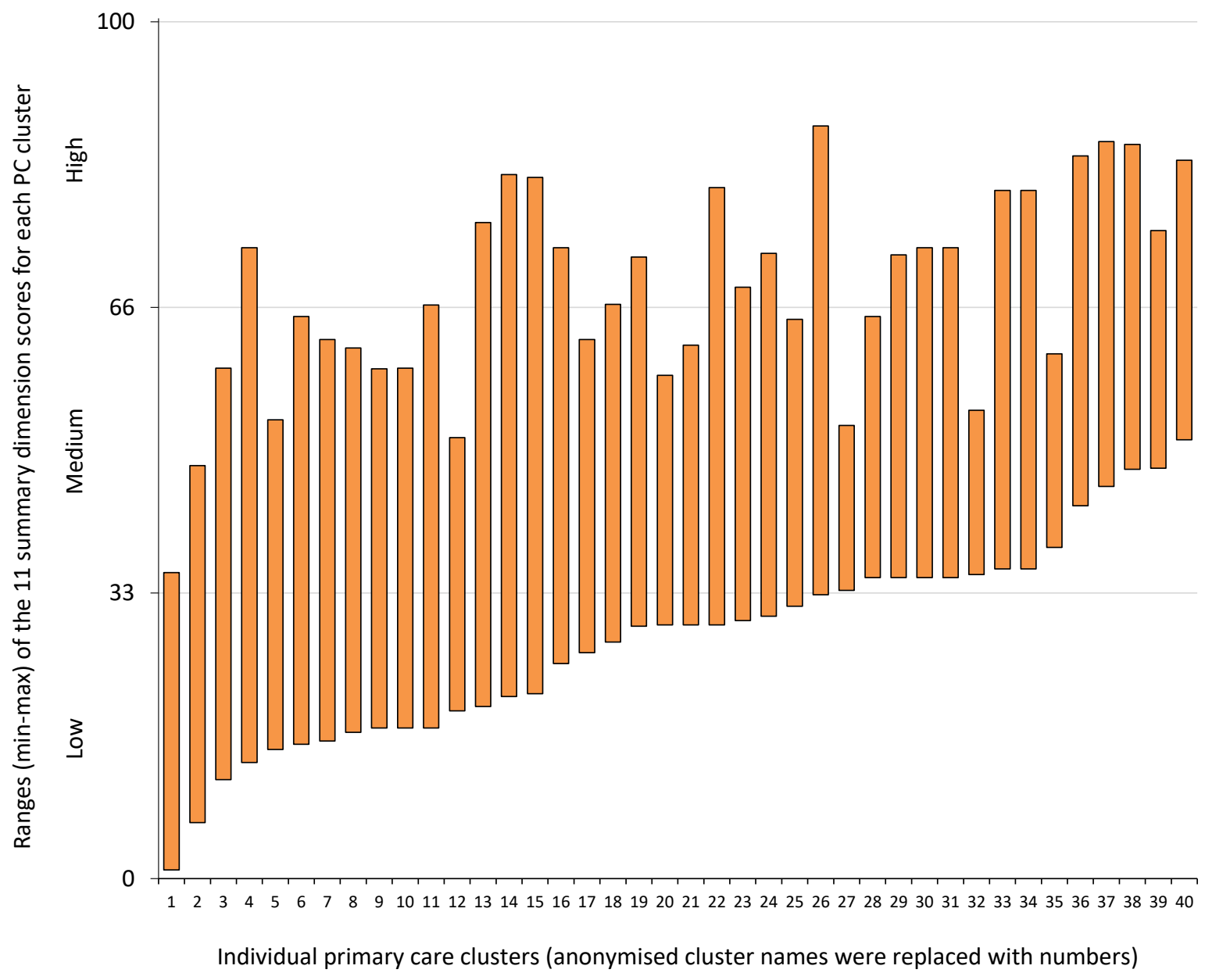

Figure 4. The distribution of PCCMA summary dimension scores across the primary care (PC) clusters. The bars represent the range (minimum to maximum) of summary scores for the 11 PCCMA systemic dimensions, corresponding to each individual cluster $(N=40)$.

\section{Discussion}

The present work represents the development and first application of a measurement tool to assess PC in Wales at cluster level. The multidimensional nature of the PCCMA allows healthcare policy planners and managers at government, health board and PC cluster level to evaluate independent aspects of PC (e.g., coordination, efficiency, or equity of care, etc.), and focus efforts on addressing existing and emerging national and local priorities. The PCCMA uses a novel set of indicators to assess a comprehensive range of PC systemic dimensions, related to PC structure, process and outcome, at a PC cluster level. The PCCMA does not include specific health outcome measures, and thus can complement and help explain measures 
The Primary Care Clusters Multidimensional Assessment (PCCMA)

of standardised clinical indicators, patient reported outcome measures (PROMs) and other routinely collected healthcare data, by providing a snapshot of the broadest set of systemic dimensions contributing to PC strength. At present, this is only from the perspective of cluster leads, but this instrument could allow the benchmarking of clusters for the local planning and provision of PC services, and could be used to develop a comprehensive 360 degrees assessment. Moreover, this work has international relevance for comprehensive and developed health care systems, where PC provision is planned and delivered locally at the levels comparable to Wales $(20,000-100,000$ people) .

\section{Summary of findings}

The cluster leads who took part in the telephone interviews were positive about the impact of PC clusters across Wales. Regional and national challenges to the clusters' work existed (e.g., recruitment, funding, autonomy, and integration) and progress in addressing them was variable. Notably, cluster leads reported a perception that whenever locally identified PC cluster priorities failed to align with the development plans of the health board, the clusters' funding seemed to be steered away from those priorities. This highlighted the need for a more formalised relationship between PC clusters and health boards, including the need for a formal recognition of the clusters' autonomy. Few cluster leads perceived that other clusters in their health board enjoyed a greater recognition, better relationship, and more support from the health board, while it was not immediately apparent to the cluster leads how those other clusters came to be in that position. The issue of a transparent and objective assessment is relevant here, one that would allow both PC clusters and health boards to identify areas of strength and weakness and use them to support both the allocation of funding and organisational support to the clusters. For the moment, the cluster leads' perceptions reported in the interview study remain an issue to be investigated further, but highlight an important area of study regarding the relationship between the larger and established organisations of the health boards, and the newly formed PC clusters.

Importantly, these indications are in agreement with the evidence and conclusions of the 2017 inquiry into PC clusters carried out by the National Assembly for Wales' Health, Social Care and Sport Committee.[37]

The literature review identified work of critical importance published in the last five years concerning international evaluations of PC systems. The models of evaluation most relevant for developed PC systems should cover three fundamental levels: structure, process 
The Primary Care Clusters Multidimensional Assessment (PCCMA)

and outcomes. The framework and developmental methodology used by Kringos and colleagues were adopted and expanded in the present work.[12]

Following the literature review and engagement with key stakeholders in PC in Wales, a series of indicators were identified and agreed as an appropriate and comprehensive data set to assess the level and effectiveness of PC cluster activity. The 53 indicators, covering the 11 systemic dimensions of PC, have been piloted in a measurement instrument called the PCCMA.

Almost two thirds of clusters completed the PCCMA survey. The "comprehensiveness of care" and "efficiency of care" dimensions scored highest overall, while the "continuity of care" dimension scored lowest. Interestingly, although the UK scores highly in international comparisons of PC systems, continuity of care is consistently reported as the lowest scoring dimension.[12]

There was a large variation in PCCMA summary dimension scores, across all systemic dimensions. Methodologically, this suggests that the middle anchor of the eVAS indicators showed good sensitivity and achieved its purpose to differentiate between clusters on various levels of development. Empirically, this suggests that further support is needed, in different clusters, across all dimensions of the PCCMA. Crucially, the high scores on the PCCMA dimensions were shared widely between a larger number of clusters, while the very low scores came from a narrow pocket of clusters whose leads reported a substantial need for support across all PCCMA dimensions. The identity of those clusters is protected in the current study, but the findings showed the potential of the PCCMA to identify both areas of best practice and areas of largest potential for growth, which can inform the priorities of health care policy makers, planners and managers for the development of PC clusters.

\section{Comparison with similar and ongoing assessments of similar PC structures}

The PCCMA can directly compare individual PC clusters and can reveal which clusters are scoring lower in specific systemic dimensions of PC. This could enable health boards and government healthcare managers to target specific and prompt measures to address imbalances in the development of PC clusters in areas of need.

The PCCMA uses a classical assessment framework, based on three levels (structure, process, outcome) which has a long tradition of use in healthcare systems quality improvement.[41] This framework is also employed by a recent influential PC system assessment tool (the PC Monitor).[12] The PCCMA tool diverges from the PC Monitor by using a novel set of indicators targeted at the PC clusters (rather than at the PC system as a 
whole), and by introducing an eleventh "cluster organisation" dimension. Similarly with the PC Monitor, the PCCMA is a quantitative instrument using a similar rating scale (0-100), and is designed to produce an aggregate score for each dimension of PC. This aggregate score can be further classified into "weak", "medium" and "strong" categories for reliability, since they correspond to the three descriptors (i.e., eVAS anchors) used to provide the indicator ratings. Coincidently, these three categories are also used by the PC Monitor. However, the PCCMA produces a numerical score (0-100) of a far greater granularity than the PC Monitor, to which alternative data transformations could be applied (e.g., quartiles, quintiles or deciles), notwithstanding the particular relationship between the three eVAS anchors and the three categories. Notably, like the PC Monitor, an overall score of the PCCMA (across all systemic dimensions) is not prescribed by the current methodology. At a minimum, aggregating the summary scores of each dimension into an overall score, while computationally trivial (e.g., via a simple or weighted mean, or any other algorithm), would require judgements about the importance of each dimension of PC and subsequent contribution to the overall score. While all dimensions of PC are ostensibly important, their contribution to an overall score may not automatically be equal, in all circumstances. This can be due to conceptual reasons, guided by different healthcare policies and strategies (e.g., greater emphasis of efficiency over comprehensiveness of care) and methodological reasons such as the indicator density of each dimension (i.e., some dimensions have more indicators than others, and thus, arguably, a greater domain of assessment). These considerations are a matter of healthcare policy and focus, and can easily inform the future use and calculation of the overall PCCMA aggregate score.

The breadth of indicators used in the 360 degree assessment in England has covered specific activities related to commissioning of services, but has not systematically addressed the entire PC system. This limits the ability to group indicators by specific dimensions of PC, as was done in the PCCMA, in order to inform broad areas of policy change (e.g., governance, workforce development, access to PC services, efficiency, equity, etc.). The annual 360-degree assessment has enabled benchmarking and analysis of how the CCGs have evolved, which would be enhanced by the use of the PCCMA.

Internationally, organisations in developed health care systems are looking for integrated ways of planning and delivering care at population levels similar to PC clusters in Wales (20,000-100,000 patients). Previous assessments of PC systems have been at the level of individual PC practices and community services, or at the national level. The PCCMA 
The Primary Care Clusters Multidimensional Assessment (PCCMA)

addresses the gap in between, which is increasingly important for health policy planners and large health care provider organisations.

\section{Strengths and limitations}

The PCCMA is the first comprehensive instrument to allow a systematic assessment of PC clusters on all key dimensions of PC from the perspective of cluster leads. It builds on an established PC assessment framework and its content have been developed by a broad range of PC stakeholders. In future, the PCCMA could allow benchmarking of the strength of PC clusters. However, in the present format, the PCCMA should not be seen as a definitive assessment of PC clusters. It is a snapshot from the perspective of cluster leads, which can be strengthened in three important ways. Firstly, with further validation, the PCCMA can be developed into a 360-degree instrument, allowing the assessment of the clusters from multiple agencies. This would involve obtaining assessments from all the participants at the cluster meetings (e.g. GPs, practice managers, health board managers, community teams, social care, third sector organisations, etc.). Secondly, the PCCMA data should be analysed in the context of other routinely collected clinical, demographics and cluster maturity indicators. Of immediate interest are the PC indicators produced by PHW and accepted by the Directors of PC in Wales,[42] and the maturity matrix for locality network.[43] This could help explore and explain associations between ratings of key PC dimensions, and variations between clusters from the same health board, or with similar demographic characteristics. Thirdly, the PCCMA instrument could identify clusters that need more support, health-board level challenges, and variations between and within individual dimensions of PC. Thus, completion rates and continual assessment remain important considerations. Similar to the assessment model in England, a 360-degree version of the PCCMA could be administered annually and allow the benchmarking of individual clusters and health boards to improve the local planning and delivery of PC services.

\section{Conclusions}

The PCCMA improves the information available to national policy makers and local partners about the development of the PC clusters and can contribute to finding ways to increase the strength of PC. The involvement of local front line PC providers and patients is paramount for the development of the clusters. This is particularly the case for longitudinal assessments, which will allow benchmarking. The development of the PCCMA and its associated findings will allow the monitoring of change, the identification of areas of need 
The Primary Care Clusters Multidimensional Assessment (PCCMA)

and sharing of best practice. The PCCMA can also complement specific impact evaluation and healthcare outcomes measures on particular priorities of PC health policy (e.g., equity, efficiency and quality of care). Moreover, the systematic and comprehensive assessment of PC clusters can be of interest to GPs embracing new ways of working, PC federations and PC leads. Finally, this instrument can be applied in all countries with a strong PC base, where care is planned and organised at similar scales, and measurement is needed for continuous quality improvement. 
The Primary Care Clusters Multidimensional Assessment (PCCMA)

\section{References}

[1] Addicott R, Ham C. Commissioning and funding general practice: Making the case for family care networks. Kings Fund; 2014. https://www.kingsfund.org.uk/sites/files/kf/field/field_publication_file/commissioningand-funding-general-practice-kingsfund-feb14.pdf, (accessed on November 25, 2017)

[2] Kringos DS, Boerma W, van der Zee J, Groenewegen P. Europe's strong primary care systems are linked to better population health but also to higher health spending. Health Aff (Millwood) 2013; 32(4):686-94. doi: 10.1377/hlthaff.2012.1242.

[3] Kessler R, Stafford D, editors. Collaborative medicine case studies: Evidence in practice. New York, NY: Springer Science \& Business Media, 2008.

[4] J. Borkan, C.B. Eaton, D. Novillo-Ortiz, P. Rivero Corte, \& A.R. Jadad. Renewing Primary Care: Lessons Learned From The Spanish Health Care System. Health Aff 2010; 29(8). https://doi.org/10.1377/hlthaff.2010.0023.

[5] Ministero della Salute. Anagrafi ASL e strutture e contesto demográfico, 2014. http://www.salute.gov.it/portale/temi/p2_6.jsp?lingua=italiano\&id=3826\&area=statistic heSSN\&menu=vuoto (accessed Apr 14, 2018).

[6] B.J. Manns, M. Tonelli, J. Zhang, D.J.T. Campbell, P. Sargious, B. Ayyalasomayajula, et al. Enrolment in primary care networks: impact on outcomes and processes of care for patients with diabetes. CMAJ 2012; 184(2):E144-152. doi:10.1503/cmaj.110755.

[7] Ahgren B, Axelsson R. Determinants of integrated health care development: chains of care in Sweden. Int J Health Plann Manage 2007; 22(2):145-157. doi:10.1002/hpm.870

[8] Australian Primary Care Collaboratives - Pioneering Change. https://apcc.org.au/ (accessed Apr 14, 2018).

[9] A.W. Knight, D. Ford, R. Audehm, S. Colagiuri, J. Best. The Australian Primary Care Collaboratives Program: improving diabetes care. BMJ Qual Saf 2012; 21(11):956963. doi:10.1136/bmjqs-2011-000460.

[10] Taket AR, Curtis SE. Locality Planning for Health Care: A Case Study in East London Area. 1989;21(4):357-364. Stable URL: https://www.jstor.org/stable/20000060

[11] Bob H. Decentralisation and Primary Care Groups: a paradigm shift for the National Health Service in England? Policy \& Politics 1999;27(2):159-172. doi: https://doi.org/10.1332/030557399782227308 
The Primary Care Clusters Multidimensional Assessment (PCCMA)

[12] D. Kringos, W. Boerma, Y. Bourgueil, T. Cartier, T. Dedeu, T. Hasvold, et al. The strength of primary care in Europe: an international comparative study. BJGP 2013; 63(616):e742-750.

[13] Donabedian A. Explorations in quality assessment and monitoring Vol. 1. The Definition of quality and approaches to its assessment. Ann Arbor, MI: Health Administration Press; 1980.

[14] Sibthorpe B, Gardner K: A conceptual framework for performance assessment in primary health care. Aust J Prim Health 2007;13:96-103.

[15] Starfield B. Is primary care essential? The Lancet. 1994 Oct 22;344(8930):1129-33. doi:10.1016/S0140-6736(94)90634-3

[16] Starfield B, Shi L. Policy relevant determinants of health: an international perspective. Health policy. 2002 Jun 1;60(3):201-18. doi:10.1016/S0168-8510(01)00208-1

[17] Macinko J, Starfield B, Shi L. The contribution of primary care systems to health outcomes within Organization for Economic Cooperation and Development (OECD) countries, 1970-1998. Health services research. 2003 Jun;38(3):831-65. Doi:10.1111/1475-6773.00149

[18] Ramsay J, Campbell JL, Schroter S, Green J, Roland M. The General Practice Assessment Survey (GPAS): tests of data quality and measurement properties. Family Practice. 2000 Oct 1;17(5):372-9. https://doi.org/10.1093/fampra/17.5.372

[19] Mead N, Bower P, Roland M. The general practice assessment questionnaire (GPAQ)development and psychometric characteristics. BMC family practice. 2008 Dec;9(1):13. https://doi.org/10.1186/1471-2296-9-13

[20] Rhydderch M, Edwards A, Elwyn G, Marshall M, Engels Y, Van den Hombergh P, Grol R. Organizational assessment in general practice: a systematic review and implications for quality improvement. Journal of evaluation in clinical practice. 2005 Aug;11(4):366-78. doi:10.1111/j.1365-2753.2005.00544.x

[21] Amado CA, Dyson RG. On comparing the performance of primary care providers. European Journal of Operational Research. 2008 Mar 16;185(3):915-32. doi:10.1016/j.ejor.2006.02.052

[22] Starfield B, Cassady C, Nanda J, Forrest CB, Berk R. Consumer experiences and provider perceptions of the quality of primary care: implications for managed care. Journal of Family Practice. 1998 Mar 1;46(3):216-26.

[23] NHS England. Clinical commissioning group details. 2018. https://www.england.nhs.uk/ccg-details/ (accessed Apr 14, 2018) 
The Primary Care Clusters Multidimensional Assessment (PCCMA)

[24] Health and Social Care Act 2012. 2012.

http://www.legislation.gov.uk/ukpga/2012/7/contents/enacted (accessed Apr 14, 2018)

[25] C. Naylor, N. Curry, H. Holder, S. Ross, L. Marshall, E. Tait. Clinical commissioning groups: supporting improvement in general practice? London, UK: The Kings Fund. 2013.

https://www.kingsfund.org.uk/sites/default/files/field/field_publication_file/clinicalcommissioning-groups-report-ings-fund-nuffield-jul13.pdf (accessed Apr 14, 2018)

[26] NHS England. CCG improvement and assessment. Available from: https://www.england.nhs.uk/commissioning/ccg-assess/ (accessed Apr 14, 2018)

[27] K. Checkland, P. Allen, A. Coleman, J. Segar, I. McDermott, S. Harrison, et al. Accountable to whom, for what? An exploration of the early development of Clinical Commissioning Groups in the English NHS. BMJ Open 2013; 3(12): e003769. http://dx.doi.org/10.1136/bmjopen-2013-003769

[28] NHS England. Primary care networks. https://www.england.nhs.uk/primarycare/primary-care-networks/ (accessed on Aug 20, 2019)

[29] NHS England. NHS Shared Planning Guidance. https://www.england.nhs.uk/operational-planning-and-contracting/ (accessed on Aug 20, 2019)

[30] Scottish Government. A national clinical strategy for Scotland. 2016. http://www.gov.scot/Publications/2016/02/8699/downloads (accessed May 26, 2017)

[31] Smith GI, Mercer SW, Gillies JC, McDevitt A. Improving together: a new quality framework for GP clusters in Scotland. British Journal of General Practice. 2017; 67(660):294-295. Doi:10.3399/bjgp17X691601

[32] Northern Ireland Medical and Training Agency. GP Federations. http://www.nimdta.gov.uk/general-practice/gp-career-development/gp-federations/ (accessed on Aug 20, 2019)

[33] Royal College of General Practitioners. Primary Care Federations putting patients first. https://www.rcgp.org.uk/policy/rcgp-policy-areas/primary-care-federations-puttingpatients-first.aspx (accessed on Aug 20, 2019)

[34] NHS Wales. Health in Wales. 2017. http://www.wales.nhs.uk/nhswalesaboutus/structure (accessed on Apr 14, 2018)

[35] Welsh Assembly Government. Setting the Direction - Primary \& Community Services Strategic Delivery Programme. 2010. 
The Primary Care Clusters Multidimensional Assessment (PCCMA)

http://www.wales.nhs.uk/sitesplus/documents/829/setting\%20the\%20direction.pdf (accessed Apr 14, 2018)

[36] Welsh Government. Together for Health - A Five Year Vision for NHS in Wales. 2011. http://www.wales.nhs.uk/sitesplus/documents/829/togetherforhealth.pdf (accessed Apr 14, 2018)

[37] National Assembly for Wales - Health, Social Care and Sport Committee. Inquiry into Primary Care: Clusters. 2017.

http://www.assembly.wales/en/newhome/pages/newsitem.aspx?itemid=1768\&utm_me dium=social\&utm_campaign=SocialSignIn\&utm_source=Twitter $(\operatorname{accessed}$ Apr 14, 2018)

[38] Ritchie J, Spencer L. Qualitative data analysis for applied policy research. In: Bryman A, Burgess RG. (eds.) Analyzing qualitative data. London, UK: Routledge; 1994. p173-194.

[39] Ritchie J, Spencer L, O'Connor W. Carrying out Qualitative Analysis. In: Ritchie J, Lewis J. (eds.) Qualitative Research practice. London, UK: SAGE; 2003. p.219-263.

[40] K. Thomas, P. Myres, G. Brown, C. Wilkinson, \& H. Howson. Primary care: rapid review of models and policies. 2014.

http://www.gpone.wales.nhs.uk/sitesplus/documents/1000/Primary\%20care\%20models \%20and\%20policies-\%20rapid\%20review\%20July\%202014\%20FINAL.pdf (accessed Apr 14, 2018)

[41] Campbell SM, Roland MO, Buetow SA. Defining quality of care. Social science \& medicine. 2000;51(11):1611-25.

[42] Public Health Wales. Primary Care Annual Report 2016-17. Available at: http://www2.nphs.wales.nhs.uk:8080/PHWPapersDocs.nsf/cf3d6e123b990da080256fa 300512475/317909c432c224b9802581a2005019b4/\$FILE/08.280917\%20\%20Primary\%20Care\%20Annual\%20Report\%202016-17.pdf [accessed 26.09.2018]

[43] Welsh Government - NHS Wales. Delivering Local Health Care. Available from: https://gov.wales/docs/dhss/publications/131101planen.pdf [accessed 26.09.2018] 